\title{
Clinical Phenotype and Response to Different Lines of Therapy in Elderly with Immune Thrombocytopenia: A Retrospective Study
}

This article was published in the following Dove Press journal: Journal of Blood Medicine

\author{
Salvatrice Mancuso' \\ Melania Carlisi ${ }^{1}$ \\ Nicola Serra ${ }^{2,3}$ \\ Mariasanta Napolitano (D) \\ Simona Raso (D) ${ }^{3}$ \\ Ugo Consoli ${ }^{4}$ \\ Roberto Palazzolo 5 \\ Maria Rosa Lanza Cariccio ${ }^{6}$ \\ Sergio Siragusa' \\ 'Health Promotion Sciences, Maternal \\ and Infant Care, Internal Medicine and \\ Medical Specialties (PROMISE) \\ Department, University of Palermo, \\ Palermo, Italy; ${ }^{2}$ Department of Molecular \\ Medicine and Medical Biotechnology, \\ University Federico II of Naples, Naples, \\ Italy; ${ }^{3}$ Department of Surgical, \\ Oncological and Stomatological \\ Disciplines, University of Palermo, \\ Palermo, Italy; ${ }^{4} \mathrm{UOC}$ Ematologia ARNAS \\ Garibaldi, Catania, Italy; ${ }^{5} \mathrm{UOS}$ \\ Ematologia, Asst Valtellina e Alto Lario, \\ Sondrio, Italy; ${ }^{6}$ Dipartimento Oncologico, \\ La Maddalena, UOC Di Oncoematologia \\ e TMO, Palermo, Italy
}

Correspondence: Melania Carlisi Health Promotion Sciences, Maternal and Infant Care, Internal Medicine and Medical Specialties (PROMISE) Department,

University of Palermo, 129 Via del Vespro,

Palermo 90127, Italy

Tel +39 09I-655-4504

Fax +390916554502

Email melania.carlisi@unipa.it
Purpose: Insufficient knowledge of primary immune thrombocytopenia purpura (ITP) in the elderly, together with a lack of clinical trial data, has resulted in wide variation in treatments. Here, we present a study focused on clinical characteristics of ITP in older subjects at diagnosis integrated with the subsequent course of the disease and treatment history.

Methods: In a retrospective monoinstitutional study, we evaluated $>65$-year-old patients with primary ITP. Clinical characteristics at the time of diagnosis were described and analyzed. We aimed to delineate whether subsequent lines of therapy influenced the number of relapses. In addition to initial regimens, we reported subsequent treatments and the impact on relapse trends.

Results: A total of 50 patients (56\% males, mean age 78 years) were included. With regard to clinical variables at diagnosis, statistical significance was found for Eastern Cooperative Oncology Group performance status $1(46 \%$ of patients, $p<0.0001)$, presence of three comorbidities $(36 \%$ of patients, $p<0.0001)$, World Health Organization grade 0 bleeding $(46 \%, p=0.0001)$, and World Health Organization grade 1 bleeding $(42 \%, p=0.0009)$. For bleeding sites, the most frequent were skin or mucosa $(40 \%, p=0.0477)$. A decrease in platelet count was correlated with moderate or severe bleeding $(\rho=-0.52, p=0.0001)$ and viscera or skin/mucosa + viscera site $(\rho=-0.50, p=0.0002)$. Finally, a decreasing number of patients required treatment from first-line therapy to sixth $(p<0.0001)$. Relapse was most frequent before second-line therapy $(54 \%, p<0.0001)$ and less frequent before fivth and sixth (4\%, $p=0.0072 ; 2 \%, p=0.0027)$.

Conclusion: ITP in older age poses considerable challenges, so specific management strategies should be considered to optimize outcomes. Our findings provide evidence of an inverse relationship between lines of therapy and timing of relapses. This study does not exclude the possibility that agents used after first-line therapy may have an impact on the response and modify the unfavorable course of ITP.

Keywords: primary immune thrombocytopenia, ITP, immunogeriatrics, Tpo-receptor agonist, ITP treatment, aging

\section{Introduction}

Immune thrombocytopenia purpura (ITP) is an autoimmune bleeding disorder of increased platelet destruction and decreased platelet production that affects both children and adults. ${ }^{1}$ ITP in adults is quite distinct in its underlying cause and manifestation compared to its pediatric form. ${ }^{2,3}$ In addition, ITP in adults is a fairly heterogeneous disorder with clinical features that are influenced by many factors, including age. ${ }^{4,5}$ ITP in the elderly can be considered a special scenario in which 
studies are lacking, diagnosis challenging, and management may be difficult, due to potential comorbidities, concomitant medications, and severity of bleeding. ${ }^{6}$ ITP in older adults is more common than previously recognized, and in contrast to the most frequent autoimmune disease, ${ }^{7}$ the incidence of ITP increases with age. According to bimodal incidence, a second peak is observed in adults $>60$ years of age, reaching the greatest number of cases in men aged $>75$ years. ${ }^{8}$ With growth of the older population, ITP in the elderly is becoming increasingly important and is one of the most common benign hematological diseases related to aging. ${ }^{9}$ ITP is unpredictable in its clinical course. Therefore, the management of the disease is not based on well-established policies. The emphasis is toward treating bleeding, but also platelet counts, and considering the side effects of different therapeutic options. ${ }^{10,11}$

The greatest advance in ITP treatment during the last decade has been the development of thrombopoietinreceptor agonists (Tpo-RAs). Besides encouraging efficacy rates in all patients, a significant benefit of Tpo-RAs is their favorable safety profile that avoids immunosuppression. ${ }^{12,13}$ They appear to offer many advantages over other drugs in current use, especially in the older population. ${ }^{14,15}$ However, within the context of clinical practice, potential limitations in selecting a treatment are represented by current gaps in knowledge of the management of persistent or chronic ITP.

Despite significant advances in our understanding of this condition, the natural history of ITP in aged patients has not been systematically studied, especially in relation to treatments used initially and those used at later stages of the disease. Therefore, we aimed to study clinical features, bleeding phenotype, management, and outcomes in elderly patients at the time of ITP diagnosis. Moreover, by focusing on subsequent follow-up, we attempted to determine the number of relapses and consecutive therapeutic options.

\section{Methods}

\section{Population}

In this longitudinal cohort study, adult patients $>65$ years old with ITP were analyzed. ITP was established according to published guidelines. ${ }^{16,17}$ Subjects were ineligible for the study if they had secondary ITP or any evidence of bonemarrow deficiency. To rule out conditions that may be associated with autoimmune thrombocytopenia, basic evaluations for infections (HIV, HCV, HBV, H. pylori), autoimmune disorders, malignancy (eg, lymphoproliferative disorder) were carried out. Bone-marrow diseases were excluded through targeted diagnostic procedures. Data of 50 consecutive patients diagnosed and treated from 2007 to 2017 and observed for median follow-up of 461 (95\% CI 201.8-733.9) days at the Hematology Division of the University of Palermo were collected through an electronic database. For disease assessment and classification of ITP by thrombocytopenia duration, an international working group's recommendations were used. ${ }^{16}$ Relapse was defined as platelet count $<30,000$ or requiring rescue therapy after previous treatment.

At baseline, demographics, Eastern Cooperative Oncology Group (ECOG) performance status, occurrence of bleeding at diagnosis, bleeding degree by World Health Organization score, ${ }^{18}$ and anatomic sites of bleeding (skin, mucosal surfaces, internal organs) ${ }^{19}$ were evaluated. Also, we considered antiplatelet- or anticoagulant-drug intake, presence, nature, and severity of comorbidities as per the Cumulative Illness Rating Scale (CIRS), ${ }^{20}$ and hospital admissions for decreased platelet count. The criterion for starting treatment was platelet counts $<50 \times 10^{9} / \mathrm{L}$. Additional analyses were related to therapy response, number of relapses with subsequent lines of therapy, and trend of disease evolution during follow-up. This study was conducted in accordance with the Declaration of Helsinki and approved by the Palermo 1 Ethics Commission from P Giaccone Policlinico(approval 5/18).

\section{Statistical Analysis}

Statistical analysis was performed with MatLab statistical toolbox version 2008 (MathWorks, Natick, MA, USA) for Windows (32-bit). Data are presented as numbers and percentages for categorical variables and continuous data expressed as means $\pm \mathrm{SD}$, unless otherwise specified. Multiple-comparison $\chi^{2}$ tests were used to define significant differences among percentages if $\chi^{2}$ was positive $(p<0.05)$, then residual analysis with the $Z$-test to locate the highest or lowest significant presence was performed.

Friedman's ANOVA was used for multiple comparisons among three or more means, when the same parameter was measured under different conditions on the same subjects, and under conditions where the distribution of variables was not normal. When Friedman's ANOVA was positive $(p<0.05)$, post hoc testing on pairwise comparisons was performed. Correlation analysis was performed to evaluate significant relationships between two variables. In this case, we used Spearman's $\rho$ rankcorrelation coefficient, because the distribution of 
variables was not normal. The hypothesis that the distribution of the observations in the sample was normal was assessed with the Kolmogorov-Smirnov test. In particular, we investigated the relationship between platelet count (dependent variable) and bleeding degree at diagnosis and bleeding site at diagnosis (independent variables), considering for them the following scales:

- bleeding degree at diagnosis: $0=$ none (grade 0$), 1=$ grade $1,2=$ grade $2,3=$ grade $3,4=$ grade 4.

- bleeding site at diagnosis: $0=$ no location, $1=$ skin or muscle, $2=$ viscera, $3=$ skin or muscle and viscera.

In addition, we investigated the relationship between severity of bleeding episodes (dependent variable) and antiplatelet and anticoagulant treatments (independent variable), assigning values for antiplatelet and anticoagulant treatments of $0=$ no and $1=$ yes. Finally, $p<0.05$ was considered significant.

\section{Results}

In Table 1, baseline demographics and disease characteristics of the ITP study group are shown. As can be seen, 50 consecutive patients were analyzed: $56 \%$ (28 of 50) males and $44 \%$ (22 of 50 ) females, with mean age of $74.86 \pm 6$ (66-97years. Mean value of platelets was 21.48 $\pm 22.27 \times 10^{9} / \mathrm{L}$. Due to contemporary medical issues, hospitalization became necessary for most patients $(68 \%)$ at the time of diagnosis. In Table 2, reasons for hospitalization are reported. In two cases, the reason was platelet count $<50 \times 10^{9} / \mathrm{L}$. In all other cases, there was at least one other concurrent problem that complicated the clinical picture. However, functional status showed better ECOG performance scores, with ECOG 0 in 26\% and ECOG 1 in $46 \%$ of cases, and only $18 \%$ and $82 \%$ with ECOG 2, ECOG 3, and ECOG 4, respectively. In regard to bleeding phenotype, slightly more than half the patients $(56 \%, 27$ of 50) suffered from bleeding, with a tendency toward a low degree ( $42 \%$ of grade 1$)$. Only $6 \%$ of patients had mild bleeding (grade 2 ) and in the remaining $6 \%$ severe bleeding occurred (grade 3). In cases of bleeding, the sites involved were mainly skin and/or mucosa $(40 \%)$. Other sites were viscera (4\%) and skin/mucosal + viscera in $10 \%$ of patients. Only 13 of $50(26 \%)$ patients were on antiplatelet agents and/or anticoagulants. Finally, the majority of patients had one or more comorbidities and just $4 \%$ had none, while $20 \%$ had one comorbidity, $24 \%$ had two, $36 \%$ had three, $12 \%$ had four, and $4 \%$ had six.
Table I Characteristics of the Patients at the Diagnosis

\begin{tabular}{|c|c|}
\hline & $\begin{array}{l}\text { Mean } \pm \text { SD/ } \\
\text { Percentage }\end{array}$ \\
\hline Age (years) & $74.86 \pm 6.29$ \\
\hline Sex (male) & $56 \%(28 / 50)$ \\
\hline Hospitalization (yes) & $68 \%(34 / 50)$ \\
\hline \multirow{2}{*}{$\begin{array}{l}\text { General clinical condition (ECOG } \\
\text { scale) }\end{array}$} & \\
\hline & $26 \%(13 / 50)$ \\
\hline ECOG 0 & $46 \%(23 / 50)$ \\
\hline ECOG I & $18 \%(9 / 50)$ \\
\hline ECOG 2 & $8 \%(4 / 50)$ \\
\hline ECOG 3 & $2 \%(1 / 50)$ \\
\hline \multicolumn{2}{|l|}{ ECOG 4} \\
\hline Platelets $\times 10^{9} / \mathrm{L}$ (at diagnosis) & $21.48 \pm 22.27$ \\
\hline Bleeding at diagnosis (yes) & $54 \%(27 / 50)$ \\
\hline \multicolumn{2}{|l|}{ Bleeding degree (WHO scale) } \\
\hline Grade 0 & $46 \%(23 / 50)$ \\
\hline Grade I & $42 \%(21 / 50)$ \\
\hline Grade 2 & $6 \%(3 / 50)$ \\
\hline Grade 3 & $6 \%(3 / 50)$ \\
\hline Grade 4 & 0 \\
\hline \multicolumn{2}{|l|}{ Bleeding site } \\
\hline None & $46 \%(23 / 50)$ \\
\hline Skin, mucosa & $40 \%(20 / 50)$ \\
\hline Viscera & $4 \%(2 / 50)$ \\
\hline Skin/mucosa + viscera & $10 \%(5 / 50)$ \\
\hline \multicolumn{2}{|l|}{ Antiplatelet/anticoagulant therapy } \\
\hline Data missing & $2 \%(1 / 50)$ \\
\hline Yes & $26 \%(13 / 50)$ \\
\hline No & $72 \%(36 / 50)$ \\
\hline \multicolumn{2}{|l|}{ Number of comorbidities } \\
\hline None & $4 \%(2 / 50)$ \\
\hline One & $20 \%(10 / 50)$ \\
\hline Two & $24 \%(12 / 50)$ \\
\hline Three & $36 \%(18 / 50)$ \\
\hline Four & $12 \%(6 / 50)$ \\
\hline Five & 0 \\
\hline Six & $4 \%(2 / 50)$ \\
\hline
\end{tabular}

In Table 3 types of comorbidities are reported. From a total of 124 diseases, 48 (38\%) were cardiovascular, five $(4 \%)$ respiratory, $29(23.4 \%)$ endocrinometabolic, 14 $(11.3 \%)$ renal and genitourinary, nine (7.3\%) musculo skeletal, $12(9.6 \%)$ gastrointestinal and hepatic, four $(3.2 \%)$ neurological and ocular, and three $(2.4 \%)$ psychiatric. The CIRS comorbidity score was $1.52 \pm 0.74$. It should be noted that at the time of diagnosis, one patient had had a pulmonary embolism and another deep-vein thrombosis. 
Table 2 Reasons for Hospitalization

\begin{tabular}{|c|c|}
\hline & $\%(n)$ \\
\hline Low platelet count $\left(<50 \times 10^{9} / \mathrm{L}\right)$ & $5.88 \%(2 / 34)$ \\
\hline $\begin{array}{l}\text { Low platelet count, antiplatelet agents and/or } \\
\text { anticoagulant }\end{array}$ & $2.94 \%(1 / 34)$ \\
\hline Low platelet count and comorbidities & $14.7 \mid \%(5 / 34)$ \\
\hline Low platelet count and bleeding & $20.59 \%(7 / 34)$ \\
\hline Low platelet count, bleeding, and comorbidities & $17.65 \%(6 / 34)$ \\
\hline $\begin{array}{l}\text { Low platelet count, bleeding, comorbidities, } \\
\text { antiplatelets and/or anticoagulant }\end{array}$ & $|4.7| \%(5 / 34)$ \\
\hline $\begin{array}{l}\text { Low platelet count, comorbidities, antiplatelets } \\
\text { and/or anticoagulant }\end{array}$ & $8.82 \%(3 / 34)$ \\
\hline $\begin{array}{l}\text { Low platelet count, ECOG 3, bleeding, } \\
\text { comorbidities, antiplatelets and/or anticoagulant }\end{array}$ & $5.88 \%(2 / 34)$ \\
\hline $\begin{array}{l}\text { Low platelet count, ECOG 3, bleeding, and } \\
\text { comorbidities }\end{array}$ & $2.94 \%(1 / 34)$ \\
\hline Low platelet count and ECOG 3 & $2.94 \%(1 / 34)$ \\
\hline $\begin{array}{l}\text { Low platelet count, bleeding, antiplatelets and/or } \\
\text { anticoagulant }\end{array}$ & $2.94 \%(1 / 34)$ \\
\hline Total & $68 \%(34 / 50)$ \\
\hline
\end{tabular}

Table 4 shows the scores or percentages of the parameters considered for each therapy line. We reported on overall number of relapses, lines of therapy, and associated regimens. We included data up to a total of five consecutive relapses that needed therapy, but the rate of patients who had relapsed after previous treatment decreased over time (54\% after the first line and 2\% after the fourth line). Therapeutic options included corticosteroids (prednisone/ prednisolone), intravenous immunoglobulin, rituximab, romiplostim, eltrombopag, cyclophosphamide, vincristine, and splenectomy. In some cases, further agents were added to the steroid or anti-CD20 backbone in an attempt to improve clinical outcomes.

In Table 5, we report on the statistical tests performed. For general clinical condition (ECOG), the most frequent was state $1 \quad(p<0.0001)$ and the least frequent state 4 $(\mathrm{p}=0.0027)$. For number of comorbidities, the most frequent was three $(p<0.0001)$ and the least frequent five $(p=0.0042)$. For bleeding degree according to World Health Organization score, the most frequent was no bleeding (grade 0$)(p=0.0001)$ and grade $1(p=0.0009)$, while less frequent were grades 2 and 3 and severe bleeding ( $p=0.0177$ for both). Finally, for anatomic site of bleeding, the most frequent was none $(p=0.0030)$, and skin/mucosa $(p=0.0477)$, while less frequent were viscera $(p=0.0019)$ and skin or mucosa + viscera ( $p=0.0237$ for both).

There were no significant differences for relapse timerange or therapy-response variables among therapy lines
Table 3 Comorbidities in Elderly ITP Patients at Diagnosis $(n=124)$

\begin{tabular}{|c|c|}
\hline & $\%(n)$ \\
\hline Cardiovascular & $38.7(48 / 124)$ \\
\hline Arterial hypertension & $60.4(29 / 48)$ \\
\hline Atrial fibrillation & $22.9(11 / 48)$ \\
\hline Other arrhythmias & $2.1(1 / 48)$ \\
\hline Coronary heart disease & $4.2(2 / 48)$ \\
\hline Dilated cardiomyopathy & $4.2(2 / 48)$ \\
\hline Pulmonary embolism & $2.1(1 / 48)$ \\
\hline Deep-vein thrombosis & $2.1(1 / 48)$ \\
\hline Cerebro vascular malformation & $2.1(1 / 48)$ \\
\hline Respiratory & $4.0(5 / 124)$ \\
\hline COPD & $60.0(3 / 5)$ \\
\hline OSAS & $40.0(2 / 5)$ \\
\hline Endocrine-metabolic & $23.4(29 / 124)$ \\
\hline Diabetes mellitus & $48.3(14 / 29)$ \\
\hline Hypercholesterolemia & $20.7(6 / 29)$ \\
\hline Obesity & I3.8 (4/29) \\
\hline Thyroid diseases & $13.8(4 / 29)$ \\
\hline Secondary hyperparathyroidism & $3.4(1 / 29)$ \\
\hline Kidney and genitourinary & II.3 (I4/I24) \\
\hline CKD & $28.6(4 / 14)$ \\
\hline Hydronephrosis & $7.1(1 / 14)$ \\
\hline $\mathrm{BPH}$ & $64.3(9 / 14)$ \\
\hline Muscular and skeletal & $7.3(9 / 124)$ \\
\hline Osteoarthritis & $55.6(5 / 9)$ \\
\hline Osteoporosis & $44.4(4 / 9)$ \\
\hline Gastrointestinal and liver & $9.6(12 / 124)$ \\
\hline Gastritis & $33.3(4 / 12)$ \\
\hline Colon angiodysplasia & $8.3(1 / / 2)$ \\
\hline Gilbert syndrome & $8.3(\mathrm{I} / \mathrm{I} 2)$ \\
\hline Liver steatosis & $33.3(4 / 12)$ \\
\hline Biliary lithiasis & $16.7(2 / 12)$ \\
\hline Nervous system and eye & $3.2(4 / 124)$ \\
\hline Parkinson’s disease & $50.0(2 / 4)$ \\
\hline Glaucoma & $50.0(2 / 4)$ \\
\hline Psychiatric & $2.4(3 / 124)$ \\
\hline Senile dementia & $33.3(1 / 3)$ \\
\hline Depression & $33.3(1 / 3)$ \\
\hline Affective disorder & $33.3(1 / 3)$ \\
\hline CIRS comorbidity score (mean \pm SD) & $1.52 \pm 0.74$ \\
\hline
\end{tabular}

Abbreviations: COPD, chronic obstructive pulmonary disease; OSAS, obstructive sleep-apnea syndrome; CKD, chronic kidney disease; BPH, benign prostatic hypertrophy.

one and two, two and three, and three and four ( $p=0.55$, $p=0.70$, respectively). Time ranges for linesfour/five and five/six were not considered, because there were too few patients to perform statistical analysis. In addition, for the therapy variable (patient with therapy), there was 
Table 4 Parameters for Every Therapy Line

\begin{tabular}{|c|c|c|c|c|c|c|}
\hline & First Line & Second Line & Third Line & Fourth Line & Fifth Line & Sixth Line \\
\hline Mean age (years) & $75.10 \pm 6.51$ & $74.82 \pm 5.77$ & $76.40 \pm 6.14$ & $78.15 \pm 6.33$ & $81.78 \pm 7.86$ & $76.00 \pm 0.00$ \\
\hline Therapy & $94 \%(47 / 50)$ & $54 \%(27 / 50)$ & $28 \%(14 / 50)$ & $12 \%(6 / 50)$ & $4 \%(2 / 50)$ & $2 \%(1 / 50)$ \\
\hline Corticosteroids & $59.57 \%(28 / 47)$ & $11.11 \%(3 / 27)$ & $14.29 \%(2 / 14)$ & 0 & 0 & 0 \\
\hline IVIG & 0 & $0 \%(0 / 27)$ & $7.14 \%(1 / 14)$ & 0 & 0 & 0 \\
\hline Corticosteroids + IVIG & $40.43 \%(19 / 47)$ & $22.22 \%(6 / 27)$ & $21.43 \%(3 / 14)$ & 0 & $50 \%(1 / 2)$ & 0 \\
\hline Rituximab & 0 & $14.81 \%(4 / 27)$ & $7.14 \%(1 / 14)$ & $33.33 \%(2 / 6)$ & $50 \%(1 / 2)$ & 0 \\
\hline Romiplostim & 0 & $25.93 \%(7 / 27)$ & $14.29 \%(2 / 14)$ & $16.67 \%(1 / 6)$ & 0 & $100 \%(1 / 1)$ \\
\hline Eltrombopag & 0 & $7.41 \%(2 / 27)$ & $28.57 \%(4 / 14)$ & $16.67 \%(1 / 6)$ & 0 & 0 \\
\hline rituximab + Romiplostim & 0 & $11.11 \%(3 / 27)$ & 0 & 0 & 0 & 0 \\
\hline Cyclophosphamide & 0 & $3.70 \%(1 / 27)$ & 0 & 0 & 0 & 0 \\
\hline Vincristine & 0 & $0 \%(0 / 27)$ & $7.14 \%(1 / 14)$ & 0 & 0 & 0 \\
\hline Splenectomy & 0 & $3.70 \%(1 / 27)$ & 0 & $33.33 \%(2 / 6)$ & 0 & 0 \\
\hline \multicolumn{7}{|l|}{ Therapy respons } \\
\hline Not applicable & $6 \%(3 / 50)$ & $46 \%(23 / 50)$ & $72 \%(36 / 50)$ & $88 \%(44 / 50)$ & $96 \%(48 / 50)$ & $98 \%(49 / 50)$ \\
\hline Yes & $72.34 \%(34 / 47)$ & $85.19 \%(23 / 27)$ & $71.43 \%(10 / 14)$ & $66.67 \%(4 / 6)$ & $50 \%(1 / 2)$ & $100 \%(1 / 1)$ \\
\hline \multirow[t]{2}{*}{ No } & $27.66 \%(13 / 47)$ & $14.81 \%(4 / 27)$ & $28.57 \%(4 / 14)$ & $33.33 \%(2 / 6)$ & $50 \%(1 / 2)$ & 0 \\
\hline & $\begin{array}{l}\text { First-second } \\
\text { line }\end{array}$ & $\begin{array}{l}\text { Second- third } \\
\text { line }\end{array}$ & $\begin{array}{l}\text { Third-fourth } \\
\text { line }\end{array}$ & $\begin{array}{l}\text { Fourth-fifth } \\
\text { line }\end{array}$ & \multicolumn{2}{|c|}{ Fifth-sixth line } \\
\hline $\begin{array}{l}\text { Relapse time range between two } \\
\text { consecutive therapies (days) }\end{array}$ & $292.07 \pm 488.68$ & $308.85 \pm 459.73$ & $426.67 \pm 407.20$ & $188.5 \pm 20.5$ & \multicolumn{2}{|l|}{$619 \pm 0$} \\
\hline \multicolumn{7}{|l|}{ Relapse } \\
\hline Not applicable & $8 \%(4 / 50)$ & $8 \%(4 / 50)$ & $14 \%(7 / 50)$ & $18 \%(9 / 50)$ & \multicolumn{2}{|l|}{$20 \%(10 / 50)$} \\
\hline Yes & $54 \%(27 / 50)$ & $28 \%(14 / 50)$ & $12 \%(6 / 50)$ & $4 \%(2 / 50)$ & \multicolumn{2}{|l|}{$2 \%(1 / 50)$} \\
\hline No & $38 \%(19 / 50)$ & $64 \%(32 / 50)$ & $74 \%(37 / 50)$ & $78 \%(39 / 50)$ & \multicolumn{2}{|l|}{$78 \%(39 / 50)$} \\
\hline
\end{tabular}

a significant negative trend, ie, there was a decrease in the number of patients who needed first- to sixth-line therapy $(p<0.0001)$. The same was observed for relapse $(p<0.0001)$. Notably, relapse needing treatment was most frequent in relationship to second-line therapy $(p<0.0001)$ and less frequent in relationship to fifth- and sixth-line therapy ( $p=0.0072, p=0.0027$, respectively).

Correlation analysis was performed to evaluate possible relationships between platelet count and both bleeding degree and bleeding site. We found a significant negative correlation between platelet count and bleeding degree $(R=$ $-0.52, p=0.0001)$ and bleeding site $(R=-0.50, p=0.0002)$. In other words, decreased Platelet count was correlated with moderate or severe bleeding at viscera or skin/ mucosa + viscera. Finally, no significant correlation between bleeding degree and antiplatelet and anticoagulant treatments was observed $(\rho=0.19, p=0.19)$.

\section{Discussion}

The aim of this work was to gain a more complete picture of ITP in older patients commonly seen in clinical practice. We described clinical characteristics and bleeding phenotype at onset of ITP in 50 consecutive patients older than 65 years. A slight male prevalence was observed, although it has been reported that women are more prone to autoimmune diseases than male. How important the role of sex is in developing ITP and achieving a response in older patients to date is not known. ${ }^{21}$ In this set of cases, low platelet count and associated risk of bleeding determined hospitalization for $68 \%$ of patients. On the basis of published data, hospitalization with ITP represents an economically and clinically important event and places a considerable burden on patients and society. ${ }^{22,23}$

Regarding comorbidity-data collection, 4\% of subjects did not show any associated disease, and most were affected by one to three symptomatic diseases. The proportion of patients with more comorbidities was not statistically significant. The presence of comorbidities and the clinical consequences are the key difference between ITP in the elderly and ITP in younger patients. Therefore, therapeutic management must take into account more factors in older subjects, such as higher risk of bleeding and 
Table 5 Statistical Analyses

\begin{tabular}{|c|c|}
\hline $\begin{array}{l}\text { Clinical Characteristics at } \\
\text { Diagnosis }\end{array}$ & p-value (Test Type) \\
\hline General clinical condition (ECOG) & $\begin{array}{l}<0.000 I^{*}(C) \\
\text { State I**, } p<0.000 \mathrm{I}(Z) \\
\text { State } 4^{* * *}, p=0.0027(Z)\end{array}$ \\
\hline Bleeding degree (WHO scale) & $\begin{array}{l}<0.000 I^{*}(C) \\
\text { Grade } 0 \text { (no bleeding) })^{* *}, \\
p<0.000 I(Z) \\
\text { Grade I**, } p=0.0009(Z) \\
\text { Grade } 2^{* * *}, p=0.0177(Z) \\
\text { Grade } 3^{* * *}, p=0.0177(Z) \\
\text { Grade } 4^{* * *}, p=0.0009(Z)\end{array}$ \\
\hline Bleeding sites & $\begin{array}{l}<0.000 I^{*}(C) \\
\text { No location }{ }^{* *}, p=0.0047(Z) \\
\text { Skin/mucosal**, } p=0.0477(Z) \\
\text { Visceral***, } p=0.0019(Z) \\
\text { Skin/mucosal and visceral***, } \\
p=0.0237(Z)\end{array}$ \\
\hline Number of comorbidities & $\begin{array}{l}<0.000 I^{*}(C) \\
\text { Three**, } p<0.000 \text { I }(Z) \\
\text { Five***, } p=0.0042(Z)\end{array}$ \\
\hline $\begin{array}{l}\text { Events related to therapy } \\
\text { during follow up }\end{array}$ & p-value (test type) \\
\hline $\begin{array}{l}\text { Relapse-time range (first- } \\
\text { second, second-third, third-fourth) }\end{array}$ & $0.55(\mathrm{FA})$ \\
\hline Therapy response (yes) & $0.70(\mathrm{C})$ \\
\hline $\begin{array}{l}\text { Trend among therapy lines: first-sixth } \\
\text { Therapy (yes) }\end{array}$ & $\begin{array}{l}<0.000 I^{*}(\mathrm{Ct}) \text { (negative } \\
\text { trend) }\end{array}$ \\
\hline $\begin{array}{l}\text { Trend among therapy lines: I-VI } \\
\text { Therapy response (yes) }\end{array}$ & $0.878(\mathrm{Ct})$ \\
\hline $\begin{array}{l}\text { Trend among therapy lines: first-sixth } \\
\text { Relapse (yes) }\end{array}$ & $\begin{array}{l}<0.000 I^{*}(\mathrm{Ct}) \text { (negative } \\
\text { trend) }\end{array}$ \\
\hline Relapse (Yes) & $\begin{array}{l}<0.000 I^{*}(C) \\
\text { First-second therapy**, } \\
p<0.000 \text { I }(Z) \\
\text { Fourth-fifth therapy***, } \\
p=0.0072(Z) \\
5 \text { th }-6 \text { th therapy***, } \\
p=0.0027(Z)\end{array}$ \\
\hline Linear correlation analysis & $\rho, \boldsymbol{p}$-value \\
\hline Platelet count-bleeding degree & $-0.52,0.0001 *$ \\
\hline Platelet count-bleeding site & $-0.50,0.0002^{*}$ \\
\hline $\begin{array}{l}\text { Bleeding degree-antiplatelet- } \\
\text { anticoagulant }\end{array}$ & $0.19,0.19$ \\
\hline
\end{tabular}

Notes:*Significant test;**Significant most frequent; *** Significant less frequent Abbreviations: FA, Friedman ANOVA; C, multicomparison $\chi^{2} ; \mathrm{Ct}, \chi^{2}$ for trend; $\rho$, Spearman's coefficient of rank correlation. thrombosis, concomitant medications, and monitoring of side effects of drugs for ITP. Comorbidities are frequently considered in the context of an index disease (eg, a newly diagnosed cancer), ${ }^{24}$ but the question that has not yet been addressed concerns frailty in older ITP patients. ${ }^{25}$ Frailty could also be a strong clinical indicator of increased risk of poor outcomes in subjects free of multimorbidity. ${ }^{26}$

In line with previous publications, bleeding events at baseline were not severe in our study: $42 \%$ of cases showed a low degree of bleeding and $46 \%$ of cases had none. Sites of bleeding were mainly skin and mucosa in $40 \%$ of subjects. ${ }^{2}$ Despite variability in natural history and response to therapy suggesting that primary ITP is heterogeneous, severe episodes of bleeding are relatively rare. Therefore, protective factors are thought to play a role against bleeding. ${ }^{27}$ Moreover, autoimmune disorders in the elderly have unique clinical presentations, with insidious and atypical symptoms. They are generally milder than in younger adults and can be controlled by proper therapeutic treatment. ${ }^{28}$ Other main results of our study concern the impact of the sequence of different treatments on maintenance of remission or good clinical response. Of 50 patients, only 27 received a second line of therapy, and the number of subjects in subsequent lines progressively decreased.

Our data suggest that exposure to therapeutic options of subsequent therapy after the first or second line may be favorable for good outcomes during follow-up. No significant difference was observed in the efficacy of the different therapeutic choices. Clearly, the activity of intravenous immunoglobulin, rituximab, splenectomy, Tpo-RAsm and other immunosuppressive agents used in this study was based on different mechanisms of action. Nevertheless, the potential of these different therapeutic approaches to decrease relapse rates holds significant promise in prolonging the response of platelet count. $^{29}$ Consequently, the hypothesis of considering in frontline therapy the use of drugs currently employed in subsequent lines of therapy must be considered. ${ }^{30}$ Some clinical trials have examined rituximab combination with high-dose dexamethasone. ${ }^{31,32}$ Choi et $\mathrm{al}^{33}$ tested lowdose rituximab, high-dose dexamethasone, and cyclosporine as frontline therapy for adults with ITP, with low incidence of relapse. Tpo-RAs have a good safety and efficacy profile and have become prominent drugs in this subset of patients, though long-term toxicity is unknown. Since the augmentation of thrombopoiesis is 
the key therapeutic target of Tpo-RAs, the lack of immunosuppressive effects of these agents provides a noteworthy treatment option for elderly ITP patients, possibly in the first line. ${ }^{34}$ Otherwise, intensive treatment of ITP in older patients through different lines of therapy may increase negative health outcomes, especially in frail subjects. In two independent studies, Tpo-mimetic drugs have been employed in newly diagnosed patients with ITP, with interesting preliminary data. ${ }^{35,36}$ However, neither trialfocused on elderly patients. Although our study addresses relevant aspects in a sample of elderly patients with primary ITP, our analyses are limited by the small sample. These data consequently represent exploratory measurements of outcome. However, the subjects in this study can represent the population of older ITP patients whose unmet clinical needs pose real challenges.

\section{Conclusion}

The relationship between aging and chronic diseases has become of interest for the hematological community. ITP of the elderly represents a new chapter in the field of immunogeriatrics, because the molecular framework induced by aging translates into increase prevalence of the disease in this specific age-group. The paper provides cues to help us set research priorities.

Firstly, it is necessary systematically to analyze exact underlying pathological mechanisms involved in ITP in older subjects. ITP is likely a constellation of diseases that needs to be stratified on the basis of sex and age. Secondly, a focus on detailed diagnostic workup to recognize true cases of primary ITP in the elderly is needed. In older age, various competing causes may lead to thrombocytopenia. In addition, secondary ITP is often multirefractory, with immunological mechanisms that differ from the common form of ITP. ${ }^{37}$

Because ITP in the elderly is often associated with other pathological states, further investigations are needed to evaluate whether ITP is a contributor or just correlated with them due to aging. Physiological changes in aging and age-related comorbidities can have implications for tolerance of disease and available treatments. To date, insufficient knowledge of ITP in older subsets of patients and lack of trial data have resulted in wide variation in treatment in practice.

Some drugs used after the first lines of therapy, such as Tpo-RAs, offer the most realistic chance of achieving long-term control of the disease. Our data encourage consideration of their incorporation into first-line therapy, in addition to sequencing in the resistant/relapse setting.
Finally, improved comorbidity management and patientcentered care are the key to maximizing the benefits and minimizing the risks of treatment of aged ITP patients.

\section{Ethics Approval and Informed Consent}

This study was conducted in accordance with the Helsinki Declaration and was approved by the Palermo 1 Ethics Commission from P Giaccone Policlinico (approval 5/18). The patient data accessed complied with data-protection and privacy laws.

\section{Acknowledgment}

Francesco Moscato, University of Glasgow — revised English language.

\section{Author Contributions}

All authors contributed to data analysis, drafting or revising the article, gave final approval to the version to be published, and agree to be accountable for all aspects of the work.

\section{Funding}

This research received no external funding.

\section{Disclosure}

Mariasanta Napolitano reports personal fees from Bayer, BioFVIIIx, Novonordisk, CSL Behring, Kedrion, Octapharma, and Baxalta and consultancy for Amgen outside the submitted work. The authors report no other possible conflicts of interest in this work.

\section{References}

1. John WS, Provan D, Bernadette Garvey M, Freedman J. Recent progress in understanding the pathogenesis of immune Thrombocytopenia. Curr Opin Hematol. 2010;17(6):590-595. doi:10.1097/MOH.0b013e32833eaef3

2. Cines DB, Bussel JB, Liebman HA, Luning Prak ET. The ITP syndrome: pathogenic and clinical diversity. Blood. 2009;113 (26):6511-6521. doi:10.1182/blood-2009-01-129155

3. Schulze H, Gaedicke G. Immune thrombocytopenia in children and adults: what's the same, what's different? Haematologica. 2011;96 (12):1739-1741. doi:10.3324/haematol.2011.055830

4. Cines DB, Blanchette VS. Immune thrombocytopenic purpura. $N$ Engl $J$ Med. 2002;346(13):995-1008.

5. Fogarty PF. Chronic immune thrombocytopenia in adults: epidemiology and clinical presentation. Hematol Oncol Clin North Am. 2009;23 (6):1213-1221.

6. Palandri F, Catani L, Auteri G, et al. Understanding how older age drives decision-making and outcome in immune thrombocytopenia. a single centre study on 465 adult patients. Br J Haematol. 2019;184 (3):424-430. 
7. Cooper GS, Stroehla BC. The epidemiology of autoimmune diseases. Autoimmun Rev. 2003;2(3):119-125.

8. Moulis G, Palmaro A, Montastruc JL, et al. Epidemiology of Incident Immune thrombocytopenia: a nationwide population-based study in France. Blood. 2014;124(22):3308-3315.

9. Mahévas M, Michel M, Godeau B. How we manage immune thrombocytopenia in the elderly. Br J Haematol. 2016;173(6):844-856.

10. Provan D, Arnold DM, Bussel JB, et al. Updated international consensus report on the investigation and management of primary immune thrombocytopenia. Blood Adv. 2019;3(22):3780-3817.

11. Neunert C, Terrell DR, Arnold DM, et al. American Society of Hematology 2019 guidelines for immune thrombocytopenia. Blood Adv. 2019;3(23):3829-3866. doi:10.1182/bloodadvances.2019000966

12. Lambert MP, Gernsheimer TB. Clinical updates in adult immune Thrombocytopenia. Blood. 2017;129(21):2829-2835. doi:10.1182/ blood-2017-03-754119

13. Newland A, Godeau B, Priego V, et al. Remission and platelet responses with romiplostim in primary immune thrombocytopenia: final results from a phase 2 study. $B r$ J Haematol. 2016;172 (2):262-273. doi:10.1111/bjh.13827

14. González-López TJ, Sánchez-González B, Jarque I, et al. Use of eltrombopag for patients 65 years old or older with immune thrombocytopenia. Eur J Haematol. 2019.

15. Depré F, Aboud N, Mayer B, Salama A. Efficacy and tolerability of old and new drugs used in the treatment of immune thrombocytopenia: results from a long-term observation in clinical practice. PLoS One. 2018;13(6):e0198184. doi:10.1371/journal.pone.0198184

16. Rodeghiero F, Stasi R, Gernsheimer T, et al. Standardization of terminology, definitions and outcome criteria in immune thrombocytopenic purpura of adults and children: report from an international working group. Blood. 2009;113(11):2386-2393. doi:10.1182/blood2008-07-162503

17. Provan D, Stasi R, Newland AC, et al. International consensus report on the investigation and management of primary immune thrombocytopenia. Blood. 2010;115(2):168-186. doi:10.1182/blood2009-06-225565

18. Miller AB, Hoogstraten B, Staquet M, Winkler A. Reporting results of cancer treatment. Cancer. 1981;47(1):207-214. doi:10.1002/10970142(19810101)47:1<207::AID-CNCR2820470134>3.0.CO;2-6

19. Rodeghiero F, Michel M, Gernsheimer T, et al. Standardization of bleeding assessment in immune thrombocytopenia: report from the International working group. Blood. 2013;121(14):2596-2606. doi:10.1182/blood-2012-07-442392

20. Charlson ME, Pompei P, Ales KL, MacKenzie CR. A new method of classifying prognostic comorbidity in longitudinal studies: development and validation. $J$ Chronic Dis. 1987;40(5):373-383. doi:10.1016/0021-9681(87)90171-8

21. Chapin J, Lee CS, Zhang H, Zehnder JL, Bussel JB. Gender and duration of disease differentiate responses to rituximab-dexamethasone therapy in adults with immune thrombocytopenia. Am J Hematol. 2016;91 (9):907-911. doi:10.1002/ajh.24434

22. Saleh MN, Fisher M, Grotzinger KM. Analysis of the impact and burden of illness of adult chronic ITP in the US. Curr Med Res Opin. 2009;25(12):2961-2969. doi:10.1185/03007990903362388
23. Danese MD, Lindquist K, Gleeson M, Deuson R, Mikhael J. Cost and mortality associated with hospitalizations in patients with immune thrombocytopenic purpura. Am J Hematol. 2009;84(10):631-635. doi:10.1002/ajh.21500

24. Feinstein AR. The pre-therapeutic classification of co-morbidity in chronic disease. J Chronic Dis. 1970;23(7):455-468. doi:10.1016/ 0021-9681(70)90054-8

25. Onder G, Vetrano DL, Marengoni A, Bell JS, Johnell K, Palmer K. Optimising Pharmacotherapy through Pharmacoepidemiology Network (OPPEN). Accounting for frailty when treating chronic diseases. Eur $J$ Intern Med. 2018;56:49-52. doi:10.1016/j.ejim. 2018.02.021

26. Zucchelli A, Vetrano DL, Marengoni A, et al. Frailty predicts short-term survival even in older adults without multimorbidity. Eur J Intern Med. 2018;56:53-56. doi:10.1016/j.ejim.2018.06.012

27. Boulware R, Refaai MA. Why do patients with immune thrombocytopenia (ITP) experience lower bleeding events despite thrombocytopenia? Thromb Res. 2020;187(187):154-158. doi:10.10 16/j.thromres.2020.01.020

28. Watad A, Bragazzi NL, Adawi M, et al. Autoimmunity in the elderly: insights from basic science and clinics - a mini-review. Gerontology. 2017;63(6):515-523. doi:10.1159/000478012

29. González-López TJ, Pascual C, Álvarez-Román MT, et al. Successful discontinuation of eltrombopag after complete remission in patients with primary immune thrombocytopenia. Am J Hematol. 2015;90(3): E403. doi:10.1002/ajh.23900

30. Neunert CE. Management of newly diagnosed immune thrombocytopenia: can we change outcomes? Blood Adv. 2017;1(24):2295-2301.

31. Zaja F, Baccarani M, Mazza P, et al. Dexamethasone plus rituximab yields higher sustained response rates than dexamethasone monotherapy in adults with primary immune thrombocytopenia. Blood. 2010;115(14):2755-2762.

32. Gudbrandsdottir S, Birgens HS, Frederiksen H, et al. Rituximab and dexamethasone vs dexamethasone monotherapy in newly diagnosed patients with primary immune thrombocytopenia. Blood. 2013;121 (11):1976-1981.

33. Choi PY, Roncolato F, Badoux X, Ramanathan S, Ho SJ, Chong BH. A novel triple therapy for ITP using high-dose dexamethasone, low-dose rituximab, and cyclosporine (TT4). Blood. 2015;126 (4):500-503.

34. Lucchini E, Fanin R, Cooper N, Zaja F. Management of immune thrombocytopenia in elderly patients. Eur $J$ Intern Med. 2018;58:70-76.

35. Gómez-Almaguer D, Herrera-Rojas MA, Jaime-Pérez JC, et al. Eltrombopag and high-dose dexamethasone as frontline treatment of newly diagnosed immune thrombocytopenia in adults. Blood. 2014;123(25):3906-3908.

36. Zhang L, Zhang M, Du X, Cheng Y, Cheng G. Safety and efficacy of eltrombopag plus pulsed dexamethasone as first-line therapy for immune thrombocytopenia. Br J Haematol. 2020.

37. Mahévas M, Gerfaud-Valentin M, Moulis G, et al. Characteristics, outcome, and response to therapy of multirefractory chronic immune thrombocytopenia. Blood. 2016;128(12):1625-1630.
Journal of Blood Medicine

\section{Publish your work in this journal}

The Journal of Blood Medicine is an international, peer-reviewed, open access, online journal publishing laboratory, experimental and clinical aspects of all aspect pertaining to blood based medicine including but not limited to: Transfusion Medicine; Blood collection, Donor issues, Transmittable diseases, and Blood banking logistics; Immunohematology; Artificial and alternative blood based therapeutics; Hematology; Biotechnology/nanotechnology of blood related medicine; Legal aspects of blood medicine; Historical perspectives. The manuscript management system is completely online and includes a very quick and fair peer-review system. Visit http://www.dovepress.com/testimonials.php to read real quotes from published authors. 